\title{
Translation Standards and Strategies for Trademark Names of Cosmetics*
}

\author{
Hongxin Zhao \\ University of Shanghai for Science and Technology, Shanghai, China \\ Gaofeng Yu \\ University of Shanghai for Science and Technology, Shanghai, China
}

\begin{abstract}
With the development of the society and the improvement of the people's living standard, people have gradually realized the importance of the external image while paying attention to the "inner beauty", so the cosmetics are becoming more and more popular. Proper brand name translation can not only bring consumers the feeling of beauty, but also enhance the brand level and promote products in the invisible way. This paper discusses the translation criteria and Strategies of cosmetic brand names, hoping to contribute to the development of this field.
\end{abstract}

Index Terms - imported cosmetics brand names, translation criteria, translation strategies

\section{INTRODUCTION}

People are born with a keen thirst for good looks. Since ancient times, mankind has made unremitting efforts to beautify its own cosmetics, as an exquisite makeup not only shows a person's mental outlook, but also shapes his personal charm.China's cosmetics market has developed rapidly in recent years. Since 2014, China has become the fourth largest cosmetics market in the world, only behind the United States, Brazil and Japan.(Zhang, 2016)For the vast number of consumers in China, there are various cosmetic brands to be chosen from, no matter by online shopping or by offline shopping. The variety and efficiency of such products are amazing. According to the product features, cosmetics can be divided into seven categories: emulsion, powder, beauty, perfume, shampoo, hairdressing and efficacy. It is worth noting that in recent years, imported cosmetics have played an indispensable role in people's daily necessities. An attractive brand name will undoubtedly become a kind of intangible promotion, as it not only displays the product efficiency, but also improves the brand image, thus the purchase desire can be stimulated.

Though different people have different views about the translation strategy of cosmetic brand names,a same purpose they shared must be admitted,that is, to create a pleasant feeling and a good association for consumers to entice them to consume. On the basis of faithfulness to the original, Chinese translation should try to choose the words that can arouse Chinese consumers' good associations.when Chinese cosmetic products are sold to foreign countries,the translator should also try to choose Western women's favorite words and different cultural backgrounds and taboos should be taken into consideration as well.Therefore, it is particularly necessary to summarize the translation criteria and translation strategies of cosmetic brand names.

\section{TRANSLATION STANDARDS FOR COSMETIC BRAND NAMES}

The trademark is made up of words, figures, letters and numbers. It was a "mark" made by the ancient craftsmen on their own labor results, but today is mainly used to distinguish between brands or services. "A better name can even create tens of millions of dollars in sales. (Hu, 2006, p.10)" "When consumers judge the quality of products, they rely more on brand names than price and appearance.( $\mathrm{Li}, 2003$, p.285)"As a brand name, cosmetic trademark must have its own characteristics and there are also some criteria for the translation of cosmetic brand names.

\section{A. Content Faithfulness}

Translation means transforming one language information into another. In order to accurately convey the information of the source language, faithfulness is often placed first, so the translator has to do a lot of preparatory work when translating the brand name of cosmetics, which includes understanding the culture, brand emphasis and market orientation of the company. For example, Shu Uemura is a famous Japanese cosmetic brand, and its founder is the pioneer of "fashion makeup", Mr. Shu Uemura, whose works are known for "bold colors" and "concept avant-garde". Up to this day, on the basis of scientific and technological innovation, the brand is still carrying out the concept of "nature, science and art", which combines elegance and simplicity as a whole, and is committed to creating skin care cosmetics with natural plant ingredients. The corresponding translation of Shu uemura in China is “植村秀”

\footnotetext{
* This paper is supported by USST Humanities and Social Science Foundation 2017, (NO: SK2017ZD05)
} 
(Zhicunxiu), which fully embodies the principle of faithfulness. First, "Shu” and “秀” (Xiu) are highly consistent in pronunciation. Secondly, “植” (Zhi) is easily associated with the "plant", emphasizing the raw materials of the products are selected from natural herbs, which is mild and out of irritation, in other words, all of the makeup products are based on maintenance, so there is no need to worry about the skin burden. Meanwhile, “秀” (Xiu) is often used in some common words, such as “秀丽” (Xiuli, beautiful), “时装秀” (Shizhuangxiu, fashion show), etc. While expressing "beauty", the usage of the word “秀” (Xiu) implies a tendency to be independent, unconventional and fashionable, which is in line with the psychological characteristics of women pursuing their inner true self. The information conveyed by these words precisely interprets the core connotation of Shu Uemura and shows the faithfulness of the translation.

\section{B. Language Conciseness}

After the reform and opening up, the living standard of the residents has been greatly improved. The rise of mechanized mass production and the popularity of the Internet speed up people's pace of life. According to psycholinguistic studies, people's judgments and reactions to high-frequency words are easier and quicker. In order to enhance the familiarity of brand names and their signs in the consumer's cognitive domain, translators should use high frequency words whenever possible. On the other hand, when the frequency of words is approximately the same, the degree of vocabulary cognition is related to the length of words. The longer the word, the slower the recognition speed. If a trademark must be remembered in the minds of consumers as quickly as possible, the principle of brevity is a necessity. In this era of efficiency, brand names that are concise, familiar, and easy to remember will absolutely play an important role way in pushing the brand to success. However, since the Chinese and Western languages belong to different language categories, there are obvious differences between languages, which often make the translation of the simple and powerful name of the original language translated into long and complex versions. For example, "Christian Dior” can be translated as “克里斯汀 迪奥” according to pronunciation. Considering the promotion of the brand, the translator deleted the four lengthy words in the front and revised the translation into “迪奥”. If the famous American brand "Summer's Eve" be translated directly, the translation work will be “夏天的前夕", which is made up of five words. In contrast, the “夏依” used later is more short, exquisite and easy to remember. Similarly, some brands increase the identification of trademarks by deleting certain syllables, these brands include AMPHORA AROMATICS (安芙兰), Avene (雅漾), Mamonde (梦妆), Biotherm (碧欧泉), Artistry (雅姿), Laneige (兰芝).

\section{Language Optimization}

Language can dominate or regulate readers' thinking and emotional activities, just like a good name will leave a good impression on others. In the same way, a significant brand name of cosmetics will arouse the consumers' thought and emotion and even be unforgettable to consumers. For example, the literal interpretation of "Rejoice" is "joyful, celebrating". If without any modification, there will be no sense of beauty, and the impression of the consumer will be discounted. In fact, the translation “䅇柔” can make people think of a elegant beauty with soft hair ends and silky hair roots. Since this glorious picture is very impressive, "Rejoice" has become a well-known hairdressing brand. The original translation of the German skincare brand "NIVEA" is “能维雅”. “能” is a commendatory word, which means "ability and talent", but the combination of "能" and skin care is hard to create a beautiful reverie. By contrast, the effect of “妮” on the beautification of the brand can appear. The left side of the Chinese character is “女”, so the product is visually related to women, the meaning is close to the female group, and the pronunciation is more beautiful. Therefore, these beautiful words are easier to get the favor of female groups. (Chen, 2006) The same is true in the transformation of the famous French brand “Clarins” from “克兰思” to “娇韵诗”.

\section{Cultural Adaptation}

Language is the carrier of culture. No language can isolate itself from culture and exist unilaterally. People from different countries have great differences in living environment, historical background, religious beliefs, customs and values. As a cross-cultural means of communication, the translation of brand names should be consistent with the aesthetic tastes of the audience. In the process of translation, cultural factors should be considered comprehensively, so that consumers can find more sense of belonging from the name of the brand. In other words, the translation of cosmetic brand names must be done in Rome as the Romans do. The translation of the famous international cosmetics brand “Revlon” is “露华浓”. This translation is as picturesque as a poem, which makes people think of verses in Li Bai's Plain Tune “云想衣裳花想容, 春风拂揽露华浓”. The original poem is used to describe Imperial Concubine Yang's beautiful look and costumes, which can be used to show the gorgeous feeling that make-up brings to people. The translation of "Make Up For Ever" (浮生若梦) comes from a poem of "Li Bai", who was a poet of the Tang Dynasty. The corresponding verse is “浮生若梦, 为欢几何”. The Chinese translation of the Hollywood brand “Max Factor” is “蜜丝佛陀”, which has a strong Chinese characteristics. This method of citing allusions increases the sense of identity of the potential customers ( Ren, 1994).In addition, “Kiss Me" is not translated directly into “吻我”, but translated as “奇 士美”. The reason is that Chinese culture is implicit and euphemistic and the content of literal translation is too 
straightforward, so “奇士美” is selected as the final translation to skillfully avoid embarrassment.

\section{Translation Strategies of Cosmetics Brand NAmes}

\section{A. Transliteration}

Transliteration refers to the translation of source language by using Chinese characters with similar pronunciation by following the language rule with no ambiguity. (Wang, 1998) The greatest feature of transliteration is that it can retain the rhyme beauty of the original trademark and reflect the exotic or authentic characteristics of the product. This translation method can preserve the rhythm of the source language to the greatest extent, which is mainly applicable to the translation of two cultures without corresponding concepts, such as the cosmetic brands named after the name of the founder and origin. This method can not only be faithful to the original, but also make up for the cultural gap between the two languages in cross-cultural communication. Lu Xun once mentioned that it is a very normal and ordinary thing to translate a foreigner's name through transliteration. There are numerous such examples in cosmetic brand names translation. For instance, Bobbi Brown (波比布朗), Chanel (香奈儿), Kose (高丝), Givenchy (纪梵希), Burberry (巴宝 莉), Bvlgari (宝格丽), VICHY (薇姿), Lancome (兰冦), Pond's (旁氏), Estee Lauder (雅诗兰黛), Missha (谜尚), Proya (泊莱雅), Innisfree (悦诗风吟), IPSA (茵 芙 莎), Jurique (茱莉冦), MaryKay (玫琳凯), etc.This translation method is simple and easy and the translation and brand are well matched and read smoothly, which are widely welcomed by international brands and consumers. Similarly, with the same pronunciation, the choice of elegant words can make the translation more colorful. For example, “雅诗兰黛” contains the meaning of "elegance", "poetry", "orchid-like temperament", "appropriate makeup", so a wonderful effect of "Pun" is created. It is worth mentioning that in the current cosmetics market; more than $80 \%$ of the trade names are less than six characters. The number of words in the translation is mainly about two or three, which is simple and easy to remember, and is also consistent with Chinese expression. However, if the names of some large brands of cosmetics are translated in accordance with the syllables, the number of translation words is easy to exceed the general scope, so it is necessary to use the provincial transliteration in the process of translation, such as Christian Dior (迪奥), Elizabeth Arden (雅顿), Bioderma (贝德玛).These translations are simplified from the original “克里斯汀迪奥”, “伊丽莎白雅顿”, “贝尔德玛”, and the short and exquisite words can easily shape the "brisk" brand image. In the age of the Internet, this transliteration of the omission of the superfluous syllables can save the time for consumers to memorize brands, in order to help consumers who are interested in brands understand products directly on the Internet, thereby enhancing brand recognition.

\section{B. Literal Translation}

The literal translation is to translate directly according to the name of the original cosmetics, in other words, it is translated into the same or similar target language according to the meaning of the original text. It is a common translation method in trademark translation, and is also an ideal translation method and the advantage of which is to convey the information and emotion of the original name accurately. Compared with rigid translation, this translation method maintains both the original content and the original form. Translation literally, if possible, or, appeal to free translation. Literal translation can keep the characteristics and style of the original, and avoid the "ultra vires" as much as possible. And if the original text of imported cosmetic trademark has corresponding concepts or objects in Chinese, this method will be more appropriate. The "Banana Boat", which accounts for $5 \%$ of the world's sunscreen products, is literally translated into “香蕉船”. The similar translations include Ocean story (海洋传说), Nature Republic (自然乐 园), Queen Helen (海伦皇后) etc. The translation of “Queen Helen” is not simply translated as “Queen Helen”. Instead, the order of translation is adjusted so as to make it more consistent with the expression of the target language. In addition, in order to pursue a more concise expression, the original translation can also be omitted in the literal translation process. For example, “Clé de Peau Beauté" should be literally translated into “开启美丽肌肤的钥匙” at first, but the final version is “肌肤之匙”. On the whole, this literal translation method has made little changes to the original meaning and the translation is more compatible with the composition, packaging and design of the product.

\section{Liberal Translation}

Liberal translation, also called innovative translation, is a translation method that only keeps the original content without confining to the original form. The translator only needs to translate the connotation of the brand. If great cultural differences exist in the source language and the target language and the translator cannot find the appropriate translation method according to the literal meaning, the liberal translation strategy can be adopted. However, liberal translation is not totally unconstrained. Translation is dancing in shackles. The "shackles" here are derived from internal factors such as the basic elements of the brand, cultural background, product advantages, and target customer. Some typical examples of liberal translation are collected here include Clinique (倩碧), Shiseido (资生堂), Neutrogena (露得 清), La Roche-Posay (理肤泉). Through observation, it is difficult to see the relationship between the original and the target text intuitively, but the subtlety of these translations cannot be denied. For example, the target image of the "Shiseido" company is "the pioneer of eastern aesthetics and consciousness combined with Western technology and business practice”. The translation of “资生堂” is taken from the Book of Changes. It means praising the virtues of the 
earth, as the earth has nurtured new life and created new values, which coincides with the brand's image position. Neutrogena, one of the top 100 most vibrant brands in the world, was first known for its use of a clean soap. This soap is not alkaline. When it is used, it will not cause any sense of comfort, on the contrary, the skin will return to normal $\mathrm{pH}$ after 11 minutes. With the purpose of "deep cleaning and effective oil control", the brand calls on people to embrace real self in their lives and show their real charm. The translation is a perfect interpretation of the enterprise concept.

\section{Combined Translation Method}

Combined translation method, as the term suggests, is a combination of various translation methods. According to the structure of the translation, it can be divided into three categories: the combination of transliteration and liberal translation, the combination of transliteration and literal translation and the combination of literal translation and liberal translation. This translation has a higher requirement for the comprehensive quality of the translator. A number of factors need to be taken into account in order to make the translation reach the maximum relevance to the original in the phonetic, semantic and expected values.

\section{Combination of transliteration and liberal translation}

This strategy is widely welcomed by a number of world-famous brands such as Biotherm (碧欧泉), Head \& Shoulder (海飞丝), Momonde (梦妆). Take “Biotherm” for example, its products contain unique mineral living cytokines Life Plankton ${ }^{\mathrm{TM}}$, which is of high purity and high activity, and is surprisingly similar to the perfect state of skin cells, can play five important functions: uniform skin color, intensive moisturizing, increasing elasticity, repairing fine lines and relieving allergy. The first two words “碧欧” are transliteration of “Bio-”, which is faithful to the original pronunciation and liberal translation method is adopted in “泉” to express the unique components of the product, so when consumers buy cosmetics, the picture in mind and brand image are more closely linked.

\section{Combination of transliteration and literal translation}

This translation method is common used in real life. The relevant examples include The Face Shop (菲诗小铺) and Etude House (伊蒂之屋). “Face” is translated into “菲诗” and “Etude” is translated into “伊蒂”, which combines both aesthetic feeling and poetic quality. “Shop” and “House” are translated literally to “小铺” and “之屋”, which appears to be more friendly to the common people. It also shows that the brand is cost-effective and suitable for all age groups.

\section{Combination of literal translation and liberal translation}

The combination of literal translation and liberal translation method can faithfully convey the original author's style and intention, and avoid “Translationese”, these specific examples include Origins (悦木之源), La Mer (海蓝之谜), The Body Shop (美体小铺). Taking “Origins” as an example, the word itself means “source, origin (源头,起源)” and its brand culture is "protecting the earth, the environment, the animals, and advocating natural skin care". The “悦木” here means protecting trees and the translation reproduces the purity of commodities in the most natural way.

\section{E. No Translation}

The no translation method is often used when the original brand name is of simplicity and of both phonology and visual beauty. From the perspective of aesthetic psychology, people will emerge a kind of expectation while perceiving something with beautiful rhythm. Taking SK-II as an example, the pronunciation of the original name can bring about a sensation of beauty and the "-"'in the middle makes the brand name distinctive and fashionable. In addition, the length of original brand name is perfect and the content is easy to remember, so non translation is a wise strategy. For instance, some brands like Kiko, Za, M.A.C, SK-II, DHC, LG, CK, HR, NYX, etc. also cater to the aesthetic taste of consumers by adopting non translation method, thus the language appeal of the brand name can be deepened.

\section{CONCLUSION}

Since entering the new century, the competition in the cosmetics market has become increasingly fierce. On the one hand, the world's major cosmetic brands have launched global marketing in order to gain greater global market. On the other hand, after several years' development, cosmetics brands in China are also stepping up their internationalization, so the translation of brand names for cosmetics is becoming more and more frequent. In order to get the recognition of consumers in other countries and regions, the relevant translation must respect the culture of the host country, conform to the language habits of the target country and meet the consumer's aesthetic psychological needs, so as to win more consumers and markets. In the cosmetics industry, the translation of brand names with distinctive features is one of the favorable factors for businesses to compete in the international market. In order to achieve the purpose of marketing, the translator should make a good reserve of knowledge with the standard of "content faithfulness, language conciseness, content optimization, cultural adaptation" and translate based on specific practice in order to achieve the marketing goal of an enterprise.

\section{REFERENCES}

[1] Chen Jingmei, Song Dewen. (2006). The pragmatic principles of trademark translation. Market modernization, 19 , 82-83.

[2] Hu Kaibao, Hu Shirong. ( 2006). On the explanatory power of reception theory for translation studies. Chinese translation, 3 , $10-14$. 
[3] Li Ying. (2003). Equivalent translation of English and Chinese trademark words. Journal of Southwest University for Nationalities: Humanities and Social Sciences, 6,285-290.

[4] Ren Huaiping, Sun Cuilan. (1994). Logic and Translation: a glimpse of Chinese translation, 4, 45-50.

[5] Wang Zhikui, Ren Hui Ping. (1998). A collegiate course in English-Chinese translation. Shandong: Shandong University press.

[6] Zhang Youming. (2016).Translator's marketing awareness in trademark translation. China Science and technology translation, 29 (4), 25-28.

Hongxin Zhao was born in Henan province, China. She is currently a postgraduate in the College of Foreign Languages, University of Shanghai for Science and Technology, Shanghai, China. Her major is Master of Translation and Interpretation.

Gaofeng Yu graduated from Nankai University in 1988. He is currently an Associate Professor at University of Shanghai for Science and Technology. His research interests mainly are cognitive linguistics and translation theory and practice. 